\title{
In a Heartbeat: Light and Cardiovascular Physiology
}

\author{
Sarah L. Chellappa ${ }^{1,2}$, Ruta Lasauskaite ${ }^{3}$ and Christian Cajochen ${ }^{3 *}$
}

'Medical Chronobiology Program, Division of Sleep and Circadian Disorders, Brigham and Women's Hospital, Boston, MA, United States, ${ }^{2}$ Division of Sleep Medicine, Harvard Medical School, Boston, MA, United States, ${ }^{3}$ Centre for Chronobiology, Psychiatric Hospital of the University of Basel, Transfaculty Research Platform Molecular and Cognitive Neurosciences, University of Basel, Basel, Switzerland

\section{OPEN ACCESS}

Edited by:

Diego A. Golombek, Universidad Nacional de Quilmes (UNQ), Argentina

Reviewed by: Ruud Buijs,

National Autonomous University of Mexico, Mexico Etienne Challet,

UPR3212 Institut des Neurosciences Cellulaires et Intégratives (INCI), France

*Correspondence: Christian Cajochen christian.cajochen@upkbs.ch

Specialty section:

This article was submitted to Sleep and Chronobiology, a section of the journal Frontiers in Neurology

Received: 14 August 2017 Accepted: 27 September 2017 Published: 20 October 2017

Citation:

Chellappa SL, Lasauskaite $R$ and Cajochen C (2017) In a Heartbeat: Light and Cardiovascular Physiology. Front. Neurol. 8:541. doi: 10.3389/fneur.2017.00541
Light impinging on the retina fulfils a dual function: it serves for vision and it is required for proper entrainment of the endogenous circadian timing system to the 24-h day, thus influencing behaviors that promote health and optimal quality of life but are independent of image formation. The circadian pacemaker located in the suprachiasmatic nuclei modulates the cardiovascular system with an intrinsic ability to anticipate morning solar time and with a circadian nature of adverse cardiovascular events. Here, we infer that light exposure might affect cardiovascular function and provide evidence from existing research. Findings show a time-of-day dependent increase in relative sympathetic tone associated with bright light in the morning but not in the evening hours. Furthermore, dynamic light in the early morning hours can reduce the deleterious sleep-to-wake evoked transition on cardiac modulation. On the contrary, effects of numerous light parameters, such as illuminance level and wavelength of monochromatic light, on cardiac function are mixed. Therefore, in future research studies, light modalities, such as timing, duration, and its wavelength composition, should be taken in to account when testing the potential of light as a non-invasive countermeasure for adverse cardiovascular events.

Keywords: light, non-image-forming system, circadian rhythms, cardiovascular physiology, heart rate variability

\section{OUT OF SIGHT: IMPACT OF LIGHT ON BEHAVIORAL BRAIN RESPONSES}

The mammalian eye senses light for fulfilling its dual function via two detecting systems: (1) the classical visual system that serves for image formation (1) and (2) the non-image-forming (NIF) system, which besides unconscious vision and activating early visual systems (2) affects a myriad of physiological and behavioral responses (3-7). Importantly, while these two systems differ in terms of their functions, growing evidence indicates that their complete dichotomy is outdated at the eye and brain levels (8-11). Thus, it is more likely that numerous outputs of our physiology and behavior are affected by a multi-dimensional system which can be divided into different networks. NIF effects are mostly-but not exclusively (10)-driven by melanopsin-a photopigment found in intrinsically photosensitive retinal ganglion cells (ipRGC) (3), which also play an important role as relay to transmit NIF effects coming from the classical visual system (9). These photoreceptors essentially detect environmental irradiance and exhibit maximal sensitivity to short wavelength light (blue, peak sensitivity $480 \mathrm{~nm})(3,4,12)$. Melanopsin ipRGCs typically display a low spatial resolution, long response latencies in contrast to fast responding cones and 
rods, can integrate photic energy even beyond the duration of a given light exposure, and are also involved in the detection of motion and, patterns $(2-4,9,10,13-15)$. These slow kinetics could be a potential factor underlying long-term light effects on human physiology and behavior, such that-apart from its acute effects (16) - it also impacts on, i.e., skin temperature, melatonin rhythms, and sleep-wake regulation, even after light exposure is over (17-20).

The ipRGCs directly project via the retino-hypothalamic tract to the suprachiasmatic nuclei (SCN) within the anterior hypothalamus, commonly deemed as the primary circadian oscillator $(7,21)$. The SCN, in turn, projects multisynaptically to the pineal gland (22) (associated with melatonin synthesis) and to numerous brain regions that receive input from the visual photoreceptor system, as, for instance, the lateral geniculate nucleus, superior colliculus, and olivary pretectal nucleus which is a essential node for the pathway for pupillary constriction (5, 23, 24). The melanopsin-expressing ipRGCs are also directly connected to regions which are regulating the sleep-wake cycle (25-27), including the ventrolateral preoptic nucleus (VLPO; linked to sleep-wake regulation), the subparaventricular nucleus/zone of the hypothalamus (SPVZ; linked to sleep regulation and to motor activity), and the lateral hypothalamus containing orexin (hypocretin) wake-promoting neurons (23, 24, 28).

Early animal anatomical and functional studies showed that light information conveyed to the SCN affects melatonin secretion from the pineal gland $(22,29-31)$ and glucocorticoid secretion from the adrenal cortex $(32,33)$. Furthermore, in rodents, the SCN may influence parasympathetic output to the heart via connections with pre-autonomic neurons within the hypothalamus, which may enable the 24-h sympathetic-parasympathetic balance of autonomic cardiac inputs (34). Collectively, these data suggest that the SCN can transfer its time-of-day information to various organs throughout the body like the cardiovascular system (see Figure 1 for a putative schematic diagram on the anatomical mechanisms for light modulation on the cardiovascular system via the SCN). Interestingly, hypertension seems to be related to changes in both SCN morphology and function in rodents (35, 36) and humans (37-39). This potential disturbance in hypertension-related circadian regulation, together with the incidence of tachycardia prior to the onset of hypertension (40), correspond to some of the earlier findings that highlighted a putative role of the SCN as a mediator of cardiovascular physiology (41).

NIF effects are essential for the circadian entrainment to the solar 24-h light/dark cycle and can both change the amplitude
A

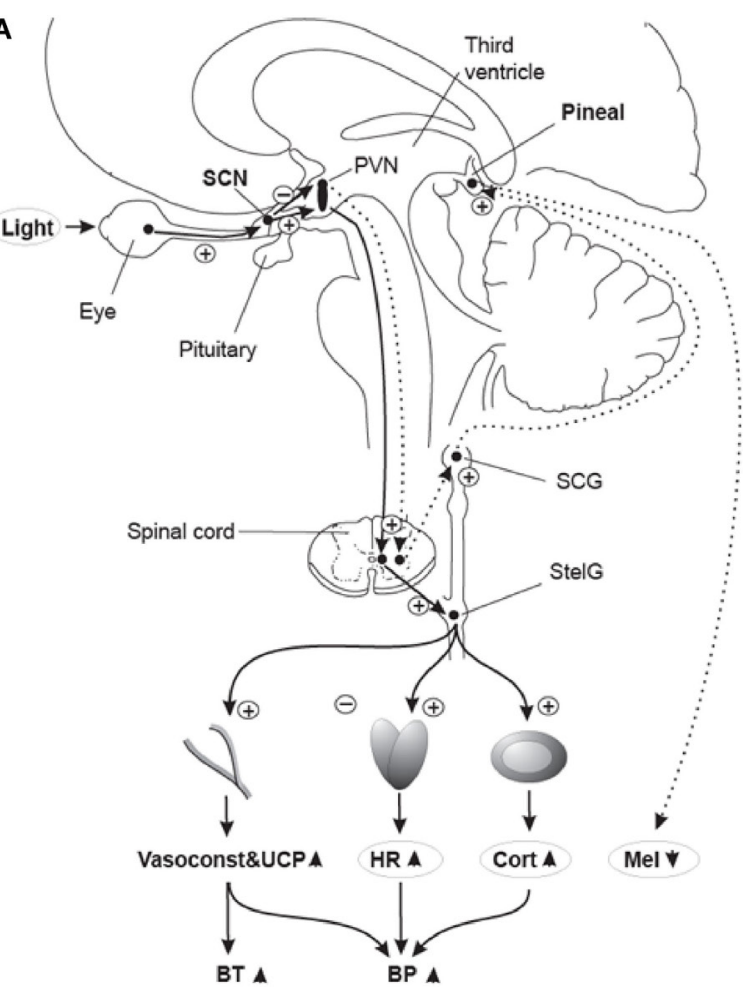

B

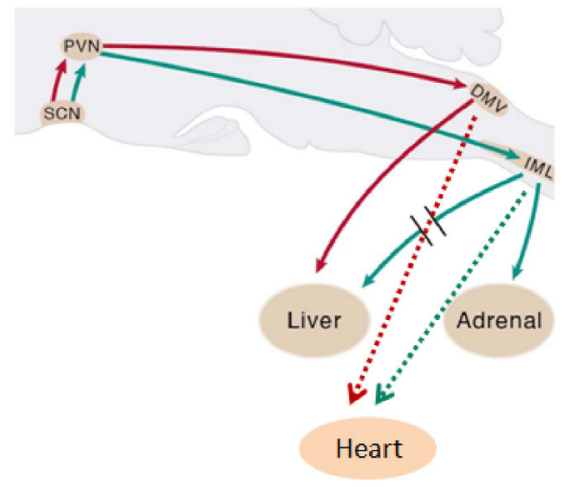

FIGURE 1 | (A) Putative light mechanisms on human cardiovascular system via the suprachiasmatic nuclei (SCN). Human SCN potentially sends different projections to different parts of the PVN to inhibit melatonin in the pineal gland, while stimulating most other SCN-driven rhythms (e.g., HR and cortisol) after light exposure. BP, blood pressure; BT, body temperature; Cort, cortisol; HR, heart rate; Mel, melatonin; PVN, paraventricular hypothalamus nucleus; SCG, superior cervical ganglion; StelG, stellate ganglion; Vasoconstr \& UCP, vasoconstriction and uncoupling protein. Continuous lines: active pathways, dotted lines: suppressed pathways. "Plus" signs: stimulation; "minus" signs: inhibition. Reproduced with permission from Scheer et al. (42). (B) Putative sympathetic and parasympathetic outputs from the SCN to peripheral organs via neurons of the rat brainstem. DMV, dorsal motor nucleus of the vagus; IML, intermediolateral spinal cord column. Red lines: parasympathetic output. Green lines: Sympathetic output. Dashed red and green lines correspond to potential output pathways. Modified from Kalsbeek et al. (34). 
and the phase of outputs of the circadian system, including, but not limited to hormone secretion (i.e., melatonin and cortisol), body temperature, sleep-wake cycle, and cardiovascular function in humans (17-20,43-45). Although photoreceptors are not directly accessible in humans, two studies have provided a putative role of ipRGCs for light affecting cognitive brain responses, including frontal cortical areas associated with executive cognitive control $(46,47)$. Furthermore, in conjunction to light's wavelength, properties like intensity, duration, and timing are essential in discovering how light differentially impacts on human physiology [for reviews, see Ref. $(16,48)$ ]. For instance, light exposure at night elicits a suppression of melatonin levels, as well as a decrease in subjective and objective indicators of sleepiness (e.g., subjective sleepiness, theta activity in waking EEG, occurrence of slow eye movements) (19, 44, 49-51). Recently, it was shown that exposure to progressively dynamic morning light can directly influence sleep inertia, well-being, and cortisol levels in humans (52-54).

Despite growing evidence for a plethora of NIF effects of light on our physiology, relatively few studies have investigated how it impacts on cardiovascular control. In the next section, we address some of the evidence which speaks to how targeted light exposure-e.g., morning vs. night light exposure, different wavelengths, illuminance levels, dynamics — affects cardiovascular function.

\section{LIGHT UP THE HEART: IMPACT OF LIGHT EXPOSURE ON CARDIOVASCULAR CONTROL}

The heart is the propelling "force for the delivery of oxygen and nutrients, for the disposal of waste and for the distribution of heat" (42). These cardiometabolic demands do not occur at an even rate throughout the 24 -h day, but rather heavily change their dynamics over the day and night (55). Importantly, the heart contains a peripheral clock that markedly modulates cardiovascular physiology (e.g., gene and protein expression, extracellular stimuli/stresses responsiveness) and its daily rhythmicity (56). Importantly, maximum risk for cardiovascular incidents is in the morning hours between 06:00 a.m. and 12:00 a.m. (57-61). Some other evidence shows an increase in occurrences in the evening (between 06:00 p.m. and midnight), hinting to a possible bimodal pattern (62). This "morning shift" in key cardiovascular regulatory mechanisms is an important characteristic of ischemic diseases like brain vascular disease, cerebral infarction, and myocardial infarction (63). Furthermore, hypertensive patients show a compromised cardiovascular anticipation to the activity period that may increase the risk of cardiovascular incidents in the early morning hours $(39,42$, $58,64)$. Yet, these adverse cardiovascular events in the morning hours cannot be explained by solely daily rhythm in external factors like body position and activity (65). Instead, it is more likely that they might be associated with circadian changes in blood pressure, vascular tone, catecholamines, platelet aggregation, increase in plasminogen activator inhibitor-1, heart rate (HR), and variation in beat-to-beat interval $(63,66,67)$. Clinical findings also suggest a small (but not trivial) 1.28-fold higher rate of acute myocardial infarction in a wide window (06:00 a.m. to 12:00 a.m.) in comparison to the rest of the day (57), bimodal peaks in the morning and evening hours (62), and stress-related contributors to adverse cardiovascular events (68). Thus, a dysfunction of the circadian clock may possibly be a risk factor for cardiovascular diseases, contributing, to some degree, to increased HR and heart rate variability (HRV) in the morning. Given that (1) the endogenous circadian timing system is best synchronized to the 24-h cycle by light (69) and (2) the SCN modulates the adrenal and the heart $(33,42)$, it is, therefore, reasonable to infer that exposure to different light modalities may affect cardiovascular function [e.g., HR, HRV, pre-ejection period (PEP)]. Thus, specific light properties, such as timing, exposure duration, intensity, wavelength, and dynamics, may well determine the magnitude of such effects.

Earlier human studies indicate that resting $\mathrm{HR}$ is affected by the day/night cycle and on the light level $(41,70)$. Accordingly, bright polychromatic light exposure (10 min of either no light, light at 100 lux or light at 800 lux) increased resting HR in the early morning hours, particularly during exposure to light at 800 lux (41), with no effects on the vagal tone, as indexed by the root mean square of the successive differences of the interbeat interval (RMSSD) (70), which is a valid index of vagal tone (71). Furthermore, exposure to bright polychromatic light at 5,000 lux for 4 h during either the day (12:00 p.m. to 04:00 p.m.) or night (12:00 a.m. to 04:00 a.m.; thus also including the early morning hours prior to an individual's wake-up time) suggest a time-of-day dependency: HR increased due to being exposed to bright light at night, but not during daytime (72). One plausible explanation for the time-of-day dependency of light on HR in the early morning hours might be related to the endogenous increase in sympathetic cardiac activity during this time window (42). The light-dependent increase in sympathetic tone may be due to light exposure in the morning hours, as sympathetic muscle nerve activity increases with morning light exposure (73). HR is also affected by light in a phase-dependent manner, which goes in concert with phase-dependent influence on sympathetic tone by morning, but not evening light (41). However, human sympathetic modulation estimated as pre-ejection period (PEP) is relatively uncoupled from the endogenous (i.e., regulated by the CNS) circadian drive and is mainly influenced by prior activation (74). Light can elicit acute cardiovascular physiological effects that depend on properties beyond timing and duration, such as its wavelength. Indeed, a 2-h exposure to monochromatic blue light $(460 \mathrm{~nm})$ in the late evening led to increased HR as compared to 550-nm monochromatic (green) light, indicating a key role for melanopsin NIF photoreceptors in modifying human HR (17).

Light effects on HRV show mixed-results in humans (75-77). For instance, higher illuminance (1,000 lux bright polychromatic white light) increased the low-frequency to high frequency (LF/ HF) HR power ratio as compared to baseline (vs. 200 lux bright polychromatic white light), which may suggest a relative increase in cardiac sympathetic activity under higher illuminance (77). Furthermore, evening ( 21:00 h) exposure to 10-min of red, green, and blue fluorescent lights of 700 lux, preceded and 
followed by 15 -min of darkness, decreased the absolute HF HR power in the episode of darkness only following blue light episode (75), suggesting that HF HR is specifically sensitive to high frequency (blue) light. Conversely, exposure to 5-min of blue, red, and white fluorescent lights may lead to a decrease in absolute HF power following exposure to only red light (76). The dissimilarity of these earlier human findings may be associated with differences in body posture (78) and respiratory frequency, the later being affected by light depending on its color (79). A recent human study measured autonomic cardio-respiratory outputs (i.e., electrocardiogram and respiration) during 6-min exposure to colored OLED (red, green, and blue lights), which was preceded and followed by 3-min of darkness under paced breathing (15 breaths/min) (80). These cardio-respiratory measurements were repeated after $45 \mathrm{~min}$ with melanopsin-stimulating photon flux density (MSPFD) of $0.00,0.10$, and $0.20 \mu \mathrm{mol} / \mathrm{m}^{2} / \mathrm{s}$, respectively. Accordingly, $\mathrm{HF}(0.20-0.30 \mathrm{~Hz})$ power had a greater decrease with blue light in comparison to red and green lights. Furthermore, HF power decreased with blue light with $0.20 \mu \mathrm{mol} /$ $\mathrm{m}^{2} / \mathrm{s}$ MSPFD, but not with that with 0.10 or $0.04 \mu \mathrm{mol} / \mathrm{m}^{2} / \mathrm{s}$, suggesting a dose-dependent effect to blue light exposure. HF power especially between 0.15 and $0.40 \mathrm{~Hz}$, also called the respiratory band, reflects vagal tone to control HR (80). In this context, one may speculate that blue OLED light exposure may result in a vagal cardiac suppression through melanopsin-dependent NIF effects, which might ultimately shift the state of our body from a resting mode to an arousal one similar to animal data (27).

Collectively, light exposure impacts cardiovascular physiology, as indexed by its effects on HR and HRV, which may be associated with its effects on the underlying temporal orchestration set up by the endogenous circadian system $(41,70)$. In this context, strategies for the "optimizing" internal biological rhythms for regulation of cardiovascular events should lead to counteracting potential adverse events during the vulnerable morning hours. Interestingly, sleep-wake transitions in the early morning hours are associated with a relative increase in sympathetic activation in comparison to the rest of the day (81), which highlights the propensity for cardiac vulnerability upon awakening (66). Given the recent evidence for the progressive dynamics of light exposure on some surrogates of human peripheral physiology (e.g., cortisol levels) $(53,54)$, one may hypothesize that exposure to a dynamic rather than abrupt light exposure during the morning sleep-wake transition might impact on cardiovascular function, with a possible gradual rise HR and cardiac sympatho-vagal control. Indeed, one human study tested how HR and HRV was differentially impacted by exposure to a "naturalistic" dawn simulation light (DSL) source (progressive rise from 0 to 250 lux) with onset at 30-min before and offset at 30-min after scheduled wake-up time, as compared to a control dim light condition (82). Importantly, posture was controlled (recumbent during sleep and semi-recumbent during wake) and sleep duration was the same prior to wake-up time in both light conditions. Accordingly, DSL exposure gradually increased HR, as compared to a steeper HR increase under a control condition (82). These gradual light changes on HR dynamics were mirrored by gradual increases in cardiac sympatho-vagal modulation in DSL as compared to a control condition (Figure 2). While HRV is a potent tool typically used in physiological and pathological conditions $(83,84)$, it does not disentangle the interplay between sympathetic and parasympathetic cardiac control. These specific autonomic subsystems are modulatory reacting systems that control HR with different latent periods and time courses, such that parasympathetic effects on HR are much slower faster than parasympathetic effects (85). By applying a non-linear symbolic analysis method $(86,87)$, the
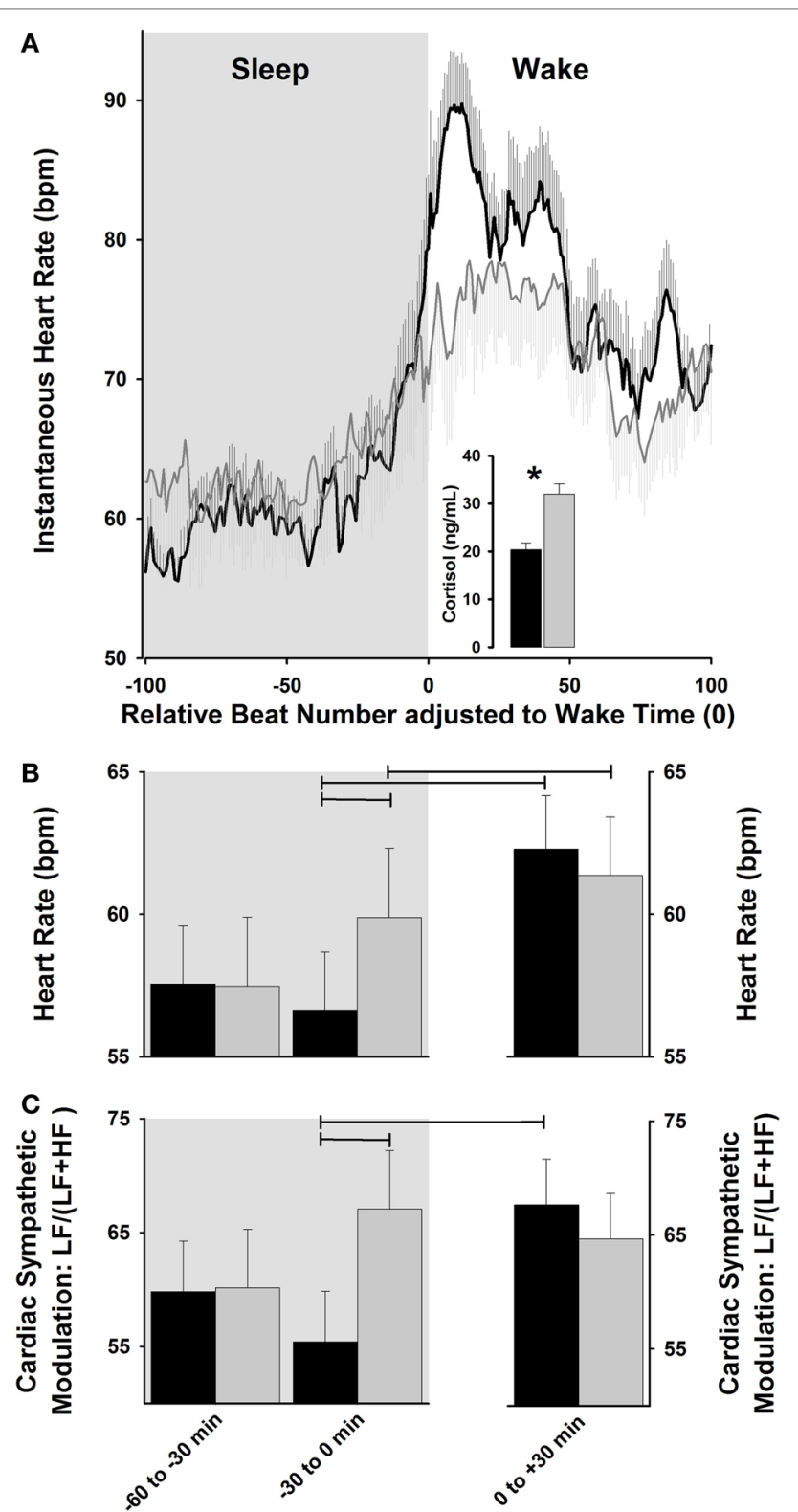

FIGURE 2 | Cardiac modulation during sleep-wake transition. (A) Exposure to dawn stimulating light [dawn simulation light (DSL); gray lines] increases instantaneous heart rate $(\mathrm{HR})$ relative to control dim light (black lines), and is associated with a higher cortisol increase. (B,C) DSL exposure (gray bars) progressively increases HR and relative cardiac sympathetic [LF/(LF + HF) ratio] levels during sleep-to-wakefulness, relative to control dim light (black bars). Horizontal lines: $p<0.05$. Reproduced with permission from Viola et al. (82). 
relative sympathetic cardiac predominance was shown to be relatively stable between both experimental light settings, whereas the relative parasympathetic cardiac activity was stable only for DSL (82). Therefore, exposure to dynamic morning light simulating natural dawn might exhibit a protective effect on the heart by an evolving preparation of cardiac physiology for the wake-up process, which is likely achieved by a subtle pre-stimulation of cardiac activity during sleep prior awakening.

Despite the impact of light exposure on markers of cardiovascular control and the potential role for timed light exposure as a countermeasure against cardiac vulnerability in the morning

\section{REFERENCES}

1. Zaidi FH, Hull JT, Peirson SN, Wulff K, Aeschbach D, Gooley JJ, et al. Shortwavelength light sensitivity of circadian, pupillary, and visual awareness in humans lacking an outer retina. Curr Biol (2007) 17:2122-8. doi:10.1016/j. cub.2007.11.034

2. Allen AE, Storchi R, Martial FP, Bedford RA, Lucas RJ. Melanopsin contributions to the representation of images in the early visual system. Curr Biol (2017) 27:1623-32. doi:10.1016/j.cub.2017.04.046

3. Provencio I, Rodriguez IR, Jiang G, Hayes WP, Moreira EF, Rollag MD. A novel human opsin in the inner retina. J Neurosci (2000) 20:600-5.

4. Panda S, Sato TK, Castrucci AM, Rollag MD, Degrip WJ, Hogenesch JB, et al. Melanopsin (Opn4) requirement for normal light-induced circadian phase shifting. Science (2002) 298:2213-6. doi:10.1126/science.1076848

5. Altimus CM, Guler AD, Villa KL, Mcneill DS, Legates TA, Hattar S. Rods-cones and melanopsin detect light and dark to modulate sleep independent of image formation. Proc Natl Acad Sci U S A (2008) 105:19998-20003. doi:10.1073/pnas.0808312105

6. Guler AD, Ecker JL, Lall GS, Haq S, Altimus CM, Liao HW, et al. Melanopsin cells are the principal conduits for rod-cone input to non-image-forming vision. Nature (2008) 453:102-5. doi:10.1038/nature06829

7. Hankins MW, Peirson SN, Foster RG. Melanopsin: an exciting photopigment. Trends Neurosci (2008) 31:27-36. doi:10.1016/j.tins.2007.11.002

8. Lucas RJ, Hattar S, Takao M, Berson DM, Foster RG, Yau KW. Diminished pupillary light reflex at high irradiances in melanopsin-knockout mice. Science (2003) 299:245-7. doi:10.1126/science.1077293

9. Allen AE, Storchi R, Martial FP, Petersen RS, Montemurro MA, Brown TM, et al. Melanopsin-driven light adaptation in mouse vision. Curr Biol (2014) 24:2481-90. doi:10.1016/j.cub.2014.09.015

10. Walmsley L, Hanna L, Mouland J, Martial F, West A, Smedley AR, et al. Colour as a signal for entraining the mammalian circadian clock. PLoS Biol (2015) 13:e1002127. doi:10.1371/journal.pbio.1002127

11. Daneault V, Dumont M, Masse E, Vandewalle G, Carrier J. Light-sensitive brain pathways and aging. J Physiol Anthropol (2016) 35:016-0091. doi:10.1186/ s40101-016-0091-9

12. Berson DM. Strange vision: ganglion cells as circadian photoreceptors. Trends Neurosci (2003) 26:314-20. doi:10.1016/S0166-2236(03)00130-9

13. Berson DM, Dunn FA, Takao M. Phototransduction by retinal ganglion cells that set the circadian clock. Science (2002) 295:1070-3. doi:10.1126/ science. 1067262

14. Hattar S, Liao HW, Takao M, Berson DM, Yau KW. Melanopsin-containing retinal ganglion cells: architecture, projections, and intrinsic photosensitivity. Science (2002) 295:1065-70. doi:10.1126/science.1069609

15. Brown TM, Tsujimura S, Allen AE, Wynne J, Bedford R, Vickery G, et al. Melanopsin-based brightness discrimination in mice and humans. Curr Biol (2012) 22:1134-41. doi:10.1016/j.cub.2012.04.039

16. Cajochen C. Alerting effects of light. Sleep Med Rev (2007) 11:453-64. doi:10.1016/j.smrv.2007.07.009

17. Cajochen C, Munch M, Kobialka S, Kräuchi K, Steiner R, Oelhafen P, et al. High sensitivity of human melatonin, alertness, thermoregulation, and heart rate to short wavelength light. J Clin Endocrinol Metab (2005) 90:1311-6. doi:10.1210/jc.2004-0957

18. Munch M, Kobialka S, Steiner R, Oelhafen P, Wirz-Justice A, Cajochen C. Wavelength-dependent effects of evening light exposure on sleep architecture hours, much remains to be established. Future studies in healthy normal and pathological aging, and in patients with increased cardiovascular risk (e.g., hypertensive patients and those with increased myocardial risk), may help to establish light as a countermeasure against the risk for acute morning cardiovascular events.

\section{AUTHOR CONTRIBUTIONS}

All authors listed have made a substantial, direct, and intellectual contribution to the work and approved it for publication.

and sleep EEG power density in men. Am J Physiol Regul Integr Comp Physiol (2006) 290:R1421-8. doi:10.1152/ajpregu.00478.2005

19. Chellappa SL, Steiner R, Blattner P, Oelhafen P, Götz T, Cajochen C. Nonvisual effects of light on melatonin, alertness and cognitive performance: can blue-enriched light keep us alert? PLoS One (2011) 6:0016429. doi:10.1371/ journal.pone.0016429

20. Chellappa SL, Steiner R, Oelhafen P, Lang D, Götz T, Krebs J, et al. Acute exposure to evening blue-enriched light impacts on human sleep. J Sleep Res (2013) 22:573-80. doi:10.1111/jsr.12050

21. Ralph MR, Foster RG, Davis FC, Menaker M. Transplanted suprachiasmatic nucleus determines circadian period. Science (1990) 247:975-8. doi:10.1126/ science. 2305266

22. Teclemariam-Mesbah R, Ter Horst GJ, Postema F, Wortel J, Buijs RM. Anatomical demonstration of the suprachiasmatic nucleus-pineal pathway. J Comp Neurol (1999) 406:171-82. doi:10.1002/(SICI)1096-9861(19990405) 406:2<171::AID-CNE3>3.3.CO;2-L

23. Hattar S, Kumar M, Park A, Tong P, Tung J, Yau KW, et al. Central projections of melanopsin-expressing retinal ganglion cells in the mouse. J Comp Neurol (2006) 497:326-49. doi:10.1002/cne.20970

24. Schmidt TM, Chen SK, Hattar S. Intrinsically photosensitive retinal ganglion cells: many subtypes, diverse functions. Trends Neurosci (2011) 34:572-80. doi:10.1016/j.tins.2011.07.001

25. Lupi D, Oster H, Thompson S, Foster RG. The acute light-induction of sleep is mediated by OPN4-based photoreception. Nat Neurosci (2008) 11:1068-73. doi: $10.1038 / \mathrm{nn} .2179$

26. Tsai JW, Hannibal J, Hagiwara G, Colas D, Ruppert E, Ruby NF, et al. Melanopsin as a sleep modulator: circadian gating of the direct effects of light on sleep and altered sleep homeostasis in Opn4(-/-) mice. PLoS Biol (2009) 7:9. doi:10.1371/journal.pbio.1000125

27. Pilorz V, Tam SK, Hughes S, Pothecary CA, Jagannath A, Hankins MW, et al. Melanopsin regulates both sleep-promoting and arousal-promoting responses to light. PLoS Biol (2016) 14:e1002482. doi:10.1371/journal.pbio. 1002482

28. Sakurai T. The neural circuit of orexin (hypocretin): maintaining sleep and wakefulness. Nat Rev Neurosci (2007) 8:171-81. doi:10.1038/nrn2092

29. Moore RY, Klein DC. Visual pathways and the central neural control of a circadian rhythm in pineal serotonin N-acetyltransferase activity. Brain Res (1974) 71:17-33. doi:10.1016/0006-8993(74)90188-7

30. McIntyre IM, Norman TR, Burrows GD, Armstrong SM. Quantal melatonin suppression by exposure to low intensity light in man. Life Sci (1989) 45:327-32. doi:10.1016/0024-3205(89)90142-2

31. Kalsbeek A, Garidou ML, Palm IF, Van Der Vliet J, Simonneaux V, Pevet P, et al. Melatonin sees the light: blocking GABA-ergic transmission in the paraventricular nucleus induces daytime secretion of melatonin. Eur J Neurosci (2000) 12:3146-54. doi:10.1046/j.1460-9568.2000.00202.x

32. Buijs RM, Wortel J, Van Heerikhuize JJ, Kalsbeek A. Novel environment induced inhibition of corticosterone secretion: physiological evidence for a suprachiasmatic nucleus mediated neuronal hypothalamo-adrenal cortex pathway. Brain Res (1997) 758:229-36. doi:10.1016/S0006-8993(97) 00234-5

33. Buijs RM, Wortel J, Van Heerikhuize JJ, Feenstra MG, Ter Horst GJ, Romijn HJ, et al. Anatomical and functional demonstration of a multisynaptic suprachiasmatic nucleus adrenal (cortex) pathway. Eur J Neurosci (1999) 11:1535-44. doi:10.1046/j.1460-9568.1999.00575.x 
34. Kalsbeek A, Scheer FA, Perreau-Lenz S, La Fleur SE, Yi CX, Fliers E, et al. Circadian disruption and SCN control of energy metabolism. FEBS Lett (2011) 585:1412-26. doi:10.1016/j.febslet.2011.03.021

35. Eilam R, Malach R, Segal M. Selective elimination of hypothalamic neurons by grafted hypertension-inducing neural tissue. J Neurosci (1994) 14:4891-902.

36. Peters RV, Zoeller RT, Hennessey AC, Stopa EG, Anderson G, Albers HE. The control of circadian rhythms and the levels of vasoactive intestinal peptide mRNA in the suprachiasmatic nucleus are altered in spontaneously hypertensive rats. Brain Res (1994) 639:217-27. doi:10.1016/0006-8993(94)91733-7

37. Guzzetti S, Dassi S, Pecis M, Casati R, Masu AM, Longoni P, et al. Altered pattern of circadian neural control of heart period in mild hypertension. J Hypertens (1991) 9:831-8. doi:10.1097/00004872-199109000-00010

38. Guzzetti S, Dassi S, Balsama M, Ponti GB, Pagani M, Malliani A. Altered dynamics of the circadian relationship between systemic arterial pressure and cardiac sympathetic drive early on in mild hypertension. Clin Sci (1994) 86:209-15. doi:10.1042/cs0860209

39. Goncharuk VD, Van Heerikhuize J, Dai JP, Swaab DF, Buijs RM. Neuropeptide changes in the suprachiasmatic nucleus in primary hypertension indicate functional impairment of the biological clock. J Comp Neurol (2001) 431:320-30. doi:10.1002/1096-9861(20010312)431:3<320::AID-CNE1073>3.0.CO;2-2

40. Dickhout JG, Lee RM. Blood pressure and heart rate development in young spontaneously hypertensive rats. Am J Physiol (1998) 274:H794-800.

41. Scheer FA, Van Doornen LJ, Buijs RM. Light and diurnal cycle affect human heart rate: possible role for the circadian pacemaker. J Biol Rhythms (1999) 14:202-12. doi:10.1177/074873099129000614

42. Scheer FA, Kalsbeek A, Buijs RM. Cardiovascular control by the suprachiasmatic nucleus: neural and neuroendocrine mechanisms in human and rat. Biol Chem (2003) 384:697-709. doi:10.1515/BC.2003.078

43. Jung CM, Khalsa SB, Scheer FA, Cajochen C, Lockley SW, Czeisler CA, et al. Acute effects of bright light exposure on cortisol levels. J Biol Rhythms (2010) 25:208-16. doi:10.1177/0748730410368413

44. Cajochen C, Frey S, Anders D, Spati J, Bues M, Pross A, et al. Evening exposure to a light-emitting diodes (LED)-backlit computer screen affects circadian physiology and cognitive performance. JAppl Physiol (2011) 110:1432-8. doi:10.1152/japplphysiol.00165.2011

45. Chang AM, Aeschbach D, Duffy JF, Czeisler CA. Evening use of light-emitting eReaders negatively affects sleep, circadian timing, and next-morning alertness. Proc Natl Acad Sci U S A (2015) 112:1232-7. doi:10.1073/pnas. 1418490112

46. Vandewalle G, Collignon O, Hull JT, Daneault V, Albouy G, Lepore F, et al. Blue light stimulates cognitive brain activity in visually blind individuals. J Cogn Neurosci (2013) 25:2072-85. doi:10.1162/jocn_a_00450

47. Chellappa SL, Ly JQ, Meyer C, Balteau E, Degueldre C, Luxen A, et al. Photic memory for executive brain responses. Proc Natl Acad Sci U S A (2014) 111:6087-91. doi:10.1073/pnas.1320005111

48. Vandewalle G, Maquet P, Dijk DJ. Light as a modulator of cognitive brain function. Trends Cogn Sci (2009) 13:429-38. doi:10.1016/j.tics.2009.07.004

49. Cajochen C, Brunner DP, Kräuchi K, Graw P, Wirz-Justice A. EEG and subjective sleepiness during extended wakefulness in seasonal affective disorder: circadian and homeostatic influences. Biol Psychiatry (2000) 47:610-7. doi:10.1016/S0006-3223(99)00242-5

50. Lockley SW, Evans EE, Scheer FA, Brainard GC, Czeisler CA, Aeschbach D. Short-wavelength sensitivity for the direct effects of light on alertness, vigilance, and the waking electroencephalogram in humans. Sleep (2006) 29:161-8.

51. Chellappa SL, Viola AU, Schmidt C, Bachmann V, Gabel V, Maire M, et al. Human melatonin and alerting response to blue-enriched light depend on a polymorphism in the clock gene PER3. J Clin Endocrinol Metab (2012) 97:E433-7. doi:10.1210/jc.2011-2391

52. Gimenez MC, Hessels M, Van De Werken M, De Vries B, Beersma DG, Gordijn MC. Effects of artificial dawn on subjective ratings of sleep inertia and dim light melatonin onset. Chronobiol Int (2010) 27:1219-41. doi:10.3109/ 07420528.2010 .496912

53. Van De Werken M, Gimenez MC, De Vries B, Beersma DG, Van Someren EJ, Gordijn MC. Effects of artificial dawn on sleep inertia, skin temperature, and the awakening cortisol response. J Sleep Res (2010) 19:425-35. doi:10.1111/j.1365-2869.2010.00828.x

54. Gabel V, Maire M, Reichert CF, Chellappa SL, Schmidt C, Hommes V, et al. Effects of artificial dawn and morning blue light on daytime cognitive performance, well-being, cortisol and melatonin levels. Chronobiol Int (2013) 30:988-97. doi:10.3109/07420528.2013.793196

55. Krantz DS, Kop WJ, Gabbay FH, Rozanski A, Barnard M, Klein J, et al. Circadian variation of ambulatory myocardial ischemia. Triggering by daily activities and evidence for an endogenous circadian component. Circulation (1996) 93:1364-71. doi:10.1161/01.CIR.93.7.1364

56. Martino TA, Young ME. Influence of the cardiomyocyte circadian clock on cardiac physiology and pathophysiology. J Biol Rhythms (2015) 30:183-205. doi:10.1177/0748730415575246

57. Muller JE, Stone PH, Turi ZG, Rutherford JD, Czeisler CA, Parker C, et al. Circadian variation in the frequency of onset of acute myocardial infarction. N Engl J Med (1985) 313:1315-22. doi:10.1056/NEJM198511213132103

58. Stergiou GS, Vemmos KN, Pliarchopoulou KM, Synetos AG, Roussias LG, Mountokalakis TD. Parallel morning and evening surge in stroke onset, blood pressure, and physical activity. Stroke (2002) 33:1480-6. doi:10.1161/01. STR.0000016971.48972.14

59. Tanaka A, Kawarabayashi T, Fukuda D, Nishibori Y, Sakamoto T, Nishida Y, et al. Circadian variation of plaque rupture in acute myocardial infarction. Am J Cardiol (2004) 93:1-5. doi:10.1016/j.amjcard.2003.09.002

60. Fournier S, Taffe P, Radovanovic D, Von Elm E, Morawiec B, Stauffer JC, et al. Myocardial infarct size and mortality depend on the time of day - a large multicenter study. PLoS One (2015) 10:e0119157. doi:10.1371/journal. pone. 0119157

61. Scott EM. Circadian clocks, obesity and cardiometabolic function. Diabetes Obes Metab (2015) 1:84-9. doi:10.1111/dom.12518

62. Hansen O, Johansson BW, Gullberg B. Circadian distribution of onset of acute myocardial infarction in subgroups from analysis of 10,791 patients treated in a single center. Am J Cardiol (1992) 69:1003-8. doi:10.1016/ 0002-9149(92)90854-R

63. Sato M, Matsuo T, Atmore H, Akashi M. Possible contribution of chronobiology to cardiovascular health. Front Physiol (2014) 4:409. doi:10.3389/ fphys.2013.00409

64. Goncharuk VD, Van Heerikhuize J, Swaab DF, Buijs RM. Paraventricular nucleus of the human hypothalamus in primary hypertension: activation of corticotropin-releasing hormone neurons. J Comp Neurol (2002) 443:321-31. doi:10.1002/cne.10124

65. Scheer FA, Hu K, Evoniuk H, Kelly EE, Malhotra A, Hilton MF, et al. Impact of the human circadian system, exercise, and their interaction on cardiovascular function. Proc Natl Acad Sci U S A (2010) 107:20541-6. doi:10.1073/ pnas. 1006749107

66. Boudreau P, Yeh WH, Dumont GA, Boivin DB. A circadian rhythm in heart rate variability contributes to the increased cardiac sympathovagal response to awakening in the morning. Chronobiol Int (2012) 29:757-68. doi:10.3109/ 07420528.2012.674592

67. Scheer FA, Shea SA. Human circadian system causes a morning peak in prothrombotic plasminogen activator inhibitor-1 (PAI-1) independent of the sleep/wake cycle. Blood (2014) 123:590-3. doi:10.1182/blood-2013-07517060

68. Willich SN, Lowel H, Lewis M, Arntz R, Baur R, Winther K, et al. Association of wake time and the onset of myocardial infarction. Triggers and mechanisms of myocardial infarction (TRIMM) pilot study. TRIMM Study Group. Circulation (1991) 84:VI62-7.

69. Czeisler CA, Gooley JJ. Sleep and circadian rhythms in humans. Cold Spring Harb Symp Quant Biol (2007) 72:579-97. doi:10.1101/sqb.2007.72.064

70. Scheer FA, Van Doornen LJ, Buijs RM. Light and diurnal cycle affect autonomic cardiac balance in human; possible role for the biological clock. Auton Neurosci (2004) 110:44-8. doi:10.1016/j.autneu.2003.03.001

71. Heart rate variability: standards of measurement, physiological interpretation and clinical use. Task Force of the European Society of Cardiology and the North American Society of Pacing and Electrophysiology. Circulation (1996) 93:1043-65. doi:10.1161/01.CIR.93.5.1043

72. Ruger M, Gordijn MC, Beersma DG, De Vries B, Daan S. Time-of-daydependent effects of bright light exposure on human psychophysiology: comparison of daytime and nighttime exposure. Am JPhysiol Regul Integr Comp Physiol (2006) 290:R1413-20. doi:10.1152/ajpregu.00121. 2005

73. Saito Y, Shimizu T, Takahashi Y, Mishima K, Takahashi K, Ogawa Y, et al. Effect of bright light exposure on muscle sympathetic nerve activity in human. Neurosci Lett (1996) 219:135-7. doi:10.1016/S0304-3940(96)13171-2 
74. van Eekelen AP, Houtveen JH, Kerkhof GA. Circadian variation in base rate measures of cardiac autonomic activity. Eur J Appl Physiol (2004) 93:39-46. doi:10.1007/s00421-004-1158-6

75. Schafer A, Kratky KW. The effect of colored illumination on heart rate variability. Forsch Komplementmed (2006) 13:167-73. doi:10.1159/000092644

76. Choi CJ, Kim KS, Kim CM, Kim SH, Choi WS. Reactivity of heart rate variability after exposure to colored lights in healthy adults with symptoms of anxiety and depression. Int J Psychophysiol (2011) 79:83-8. doi:10.1016/j. ijpsycho.2010.09.011

77. Smolders KC, De Kort YA, Cluitmans PJ. A higher illuminance induces alertness even during office hours: findings on subjective measures, task performance and heart rate measures. Physiol Behav (2012) 107:7-16. doi:10.1016/j. physbeh.2012.04.028

78. Mukai S, Hayano J. Heart rate and blood pressure variabilities during graded head-up tilt. J Appl Physiol (1985) 78:212-6.

79. Edelhauser F, Hak F, Kleinrath U, Luhr B, Matthiessen PF, Weinzirl J, et al. Impact of colored light on cardiorespiratory coordination. Evid Based Complement Alternat Med (2013) 810876:31. doi:10.1155/2013/810876

80. Yuda E, Ogasawara H, Yoshida Y, Hayano J. Suppression of vagal cardiac modulation by blue light in healthy subjects. J Physiol Anthropol (2016) 35:24. doi:10.1186/s40101-016-0110-x

81. Javaheri S, Redline S. Sleep, slow-wave sleep, and blood pressure. Curr Hypertens Rep (2012) 14:442-8. doi:10.1007/s11906-012-0289-0

82. Viola AU, Gabel V, Chellappa SL, Schmidt C, Hommes V, Tobaldini E, et al. Dawn simulation light: a potential cardiac events protector. Sleep Med (2015) 16:457-61. doi:10.1016/j.sleep.2014.12.016

83. Porta A, Faes L, Mase M, D’addio G, Pinna GD, Maestri R, et al. An integrated approach based on uniform quantization for the evaluation of complexity of short-term heart period variability: application to $24 \mathrm{~h}$ Holter recordings in healthy and heart failure humans. Chaos (2007) 17:015117. doi:10.1063/1.2404630

84. Montano N, Porta A, Cogliati C, Costantino G, Tobaldini E, Casali KR, et al. Heart rate variability explored in the frequency domain: a tool to investigate the link between heart and behavior. Neurosci Biobehav Rev (2009) 33:71-80. doi:10.1016/j.neubiorev.2008.07.006

85. Guzzetti S, Borroni E, Garbelli PE, Ceriani E, Della Bella P, Montano N, et al. Symbolic dynamics of heart rate variability: a probe to investigate cardiac autonomic modulation. Circulation (2005) 112:465-70. doi:10.1161/ CIRCULATIONAHA.104.518449

86. Porta A, Tobaldini E, Guzzetti S, Furlan R, Montano N, GnecchiRuscone T. Assessment of cardiac autonomic modulation during graded head-up tilt by symbolic analysis of heart rate variability. Am J Physiol Heart Circ Physiol (2007) 293:16. doi:10.1152/ajpheart.00006.2007

87. Tobaldini E, Porta A, Wei SG, Zhang ZH, Francis J, Casali KR, et al. Symbolic analysis detects alterations of cardiac autonomic modulation in congestive heart failure rats. Auton Neurosci (2009) 150:21-6. doi:10.1016/j. autneu.2009.03.009

Conflict of Interest Statement: The authors declare that the research was conducted in the absence of any commercial or financial relationships that could be construed as a potential conflict of interest.

Copyright (C) 2017 Chellappa, Lasauskaite and Cajochen. This is an open-access article distributed under the terms of the Creative Commons Attribution License (CC $B Y)$. The use, distribution or reproduction in other forums is permitted, provided the original author(s) or licensor are credited and that the original publication in this journal is cited, in accordance with accepted academic practice. No use, distribution or reproduction is permitted which does not comply with these terms. 